\title{
O diferențiere atipică: Vaslui vs Vasluieț $t^{\dagger}$
}

\author{
Vlad Cojocaru* \\ Institutul de Filologie Română „A. Philippide”, Str. Th. Codrescu 2, 700481 Iași, România
}

\section{Despre articol \\ Istoric:}

Primit 4 iulie 2018

Acceptat 20 iulie 2018

Publicat 7 octombrie 2018

Cuvinte-cheie:

cîmp toponimic

diferențiere hidronimică

extensie toponimică

diminutiv

afluent

\begin{abstract}
Rezumat
Studiul încearcă să ofere o explicație unei microstructuri toponimice, analizînd în ce măsură aceasta se încadrează într-un tip deja prezent în lucrările de specialitate sub numele de diferențiere hidronimică. Neutralizarea unei opoziții create la nivelul numelui între un curs de apă și afluentul său principal, în urma unui proces de extensie hidronimică, este marcată în planul denominației prin substituirea formei de bază a hidronimului de către forma sa diminutivală. Pentru a urmări o eventuală evoluție a raportului de desemnare au fost utilizate surse diverse, relevante pentru o analiză a numelor atît la nivel popular, cît și oficial, consemnate în documente scrise sau înregistrate la fața locului prin anchete directe. Atestările conduc la concluzia că sîntem în prezența unei diferențieri hidronimice, cel puțin la un anumit nivel, dar nu este vorba în acest caz de extensia numelui afluentului principal asupra cursului de apă confluent.
\end{abstract}

\section{Introducere}

Orașul Vaslui situat pe rîul Vasluieț: este aceasta o ilustrare a speței Corod pe Corozel, Tecuci pe Tecucel, în consecință admițînd același tip de explicație? În cazul satului Corodul dispariția numelui vechi al pîrîului pe care este situat și de la care și-a luat numele a fost explicată de Dragoș Moldovanu:

„În mod frecvent, extensiile toponimice afectează hidronimele. Astfel, o opoziție primară între Corod (afluent al rîului Bîrlad) și Corozel (afluentul drept principal al Corodului) a fost neutralizată printr-o extensie a denotatului Corozel în două etape: mai întîi, asupra cursului inferior al Corodului, de după confluența cu Corozelul, iar apoi asupra cursului superior al Corodului, înainte de această confluență. Hidronimul Corod dispare cu totul și se creează o nouă diferențiere, după debit, între cursul principal al Corozelului (numit înainte Corod, iar acum Corozelul cu Apă) și afluentul drept al său (numit înainte Corozel, iar acum Corozelul Sec). Este probabil că această dublă extensie a fost favorizată (dacă nu cumva chiar determinată) de omonimia relativă între hidronimul și oiconimul Corod, desemnînd satul riveran”. (Moldovanu, 2014, p. XII)

Lingvistul ieșean include în aceeași categorie a extensiilor hidronimice și procese similare din alte două cîmpuri toponimice, fără o analiză individualizată pentru fiecare caz în parte, ultimele două toponime citate nefiind tratate în MDTM, I, care cuprinde numai toponime personale:

"Aceeași evoluție se constată și în alte cîmpuri hidronimice (Tecuciul și Tecucelul, Vasluiul și Vasluiețul), avînd ca rezultat crearea unei noi opoziții privative, între hidronim (cu formă diminutivală) și oiconim (orașele Tecuci și Vaslui)”. (Moldovanu, 2014, p. XII)

\footnotetext{
${ }^{\dagger} \mathrm{O}$ versiune anterioară a acestui text a fost prezentată sub formă de comunicare la simpozionul „Toponimia între istorie, geografie și lingvistică”, Iași, 10 mai 2018.

*Adresă de corespondență: vldcojocaru@yahoo.com.
} 
Vlad Cojocaru

Pentru a utiliza același raționament și în cazul perechii Vaslui /Vasluieț, ar trebui ca în rețeaua hidrografică a rîului Vaslui să identificăm un afluent important al său desemnat prin forma diminutivală a hidronimului. Mai exact, pentru a putea reface relația normală dintre cei doi componenți ai cîmpului, și anume oiconimul Vaslui și hidronimul Vasluieț, ar trebui identificat cursul de apă secundar denumit cu forma diminutivală a toponimului, care a constituit punctul de plecare în procesul de extensie a numelui afluentului la cursul principal.

1.1. În Descriptio Moldavie a lui Dimitrie Cantemir găsim menționate, într-adevăr, cele două forme ale hidronimului, Vasluiul alături de Vasluiețul, desemnînd aparent referenți diferiți, ambii avînd calitatea, în viziunea autorului, de afluenți ai Bîrladului (apud Ghibănescu, XV, p. 128 $8^{1}$ ). Cercetînd denumirile afluenților pe întregul curs al rîului, nu am găsit numele aplicat niciunuia dintre aceștia, nici în forma primară, și nici în cea diminutivală, cu excepția zonei de la izvoare. Însă este dificil de admis o extensie hidronimică plecată din această zonă. Nici configurația rețelei hidrografice a rîului Vaslui nu ne-a ajutat în identificarea unui eventual afluent principal care să stea la originea procesului de extensie toponimică, precum în cazul Corodului.

\section{Hidronimul Vaslui în surse diverse}

Pentru a încerca o explicație a modificării relației dintre componentele cîmpului toponimic ${ }^{2}$ în discuție am urmărit evoluția în timp a denumirilor utilizate pentru desemnarea rîului pe care este situat actualul municipiu Vaslui.

\subsection{Documente scrise}

Am urmărit mai întîi, în documentele publicate în colecția DRH,A, atestările pentru hidronimul care denumește rîul pe care era situat tîrgul Vaslui, ca și o eventuală atestare a formei diminutivale a acestuia. Hidronimul a fost urmărit de-a lungul întregului curs de apă, pe cursul inferior, mijlociu sau superior al rîului, cronologic, începînd cu cele mai vechi atestări.

Anul 1429: hidronimul este atestat în forma sa primară într-un act de danie a lui Alexandru cel Bun, care dăruiește panului Bena „un sat pe Vaslui, jumătate din Făurei”3 (I, p. 141).

Anul 1438: Voievozii Ilie și Ștefan întăresc panului Oană portariul „satele, pe Vaslui, anume: Brudureștii [...] și seliștea lui Fundea”́4 (I, p. 268, original slavon).

Anul 1443: Ștefan voievod întărește lui pan Moica și pan Tudor mai multe sate, printre care și cîteva „pe Vaslui” (I, p. 340, original slavon).

Anul 1472: Ștefan cel Mare întărește lui Cristea Negoiu satele „Negoieștii [...] și Ungurenii, și moara de pe Vaslui din fața Ungurenilor" (II, p. 264, copie din 1835).

Anul 1487: satul Cîrjanii „pe Sărata ${ }^{6}$, partea dinspre Vaslui” (III, p. 17, original slavon).

Anul 1491: Ștefan cel Mare cumpără „două sate pe Vasluiu din sus de tîrgul Vasluiului, anume Brudureștii [...] și satul Mărăţăi, pe Vasluiu [...] din vechiu Părtănoși” (III, p. 189, traducere veche). Din același document, cităm detalii relevante din hotarnică: „apoi trece Vasluiul la movila săpată în malul Vasluiului” (III, p. 191).

\footnotetext{
${ }^{1}$ Informația nu apare și în hărțile lui Cantemir, cf. TTRM, I 4 , s.v., unde găsim doar Vasluy Fl. și Waslui Fl.

${ }^{2}$ Pentru conceptul de 'cîmp toponimic', vezi Moldovanu (2010, p. 16-20).

3 *Făurei, sat pe Vaslui <lîngă Benești, comuna Tanacu, județul Vaslui〉; în aval de Moara Domnească.

${ }^{4}$ Brudureștii <azi Portari, comuna Zăpodeni, județul Vaslui>; Seliştea lui Fundea, pe Vaslui <lîngă Portari >.

${ }^{5}$ Ungureni <mai sus de Solești (?), comuna Solești, județul Vaslui〉; cursul mijlociu al Vasluiului.

${ }^{6}$ Afluent drept al r. Vaslui, la s. Moara Domnească.
} 
Secolul al XVI-lea: hidronimul este atestat în continuare în forma sa primară în hotarul unor sate de lîngă Șerbotești ${ }^{7}$, în descrierea acestui hotar apărînd „drumul lui Stan Preutescul prin apa Vaslui și de acolo apa Vaslui la vale, pînă la Brebi” (I, p. 418, document fals din secolul al XVI-lea).

Anul 1502: „nepoata lui Toma Solescu vinde un sat pe Vaslui, anume Solești” (III, p. 482).

Anul 1503: se vînd cinci sate pe Dobrovăț „la obîrșia Dobrovățului și a Pietroasei, pînă la obîrșia Vasluiului, la un tei [...] lîngă drumul ce merge de la Buciumi la mănăstirea Dobrovățului [...] la matca Vasluiului, pe matca Vasluiului în jos pînă la gura Dobrovățului, unde cade Dobrovățul în Vaslui" (III, p. 527).

Anul 1623: „din Dealul Vasluiului [...] trece pîrîul Sărata și ajunge la Glod”’ (XVIII, p. 21, original slavon).

Anul 1623: se vinde o ocină din satul „Strîmtură [...] cu loc de moară ce este pe rîul Vaslui” ${ }^{10}$ (XVIII, p. 25, original slavon).

Anul 1624: parte din Miclești „cu loc de mori în Vasluiu”. În același document găsim menționat „parte din poiana de la Cîrnul, și cu loc de moară în Vasluiu"11 (XVIII, p. 284).

Anul 1625: „Popa Gonțea de Solești și cu ai săi răzeși pentru o moară ce au făcut ei împreună în apa Vasluiului" (XVIII, p. 324, original românesc).

Anul 1625: este menționat satul Dușești „cu doă mori în Vasluiu” și în același document, într-o exprimare mai clară, „satul Duşaștiti ${ }^{12}$ [...] cu două mori în pîrîul Vaslui” (XVIII, p. 453, copie $\operatorname{din} 1835)$.

Anul 1628: Miron Barnovschi Moghilă dăruiește bisericii din tîrgul Vaslui „mori pe apa Vasluiului" (XIX, p. 531).

Anul 1639: vînzare în satele Nuorești și Poiana Cîrnului „cu vad de moară pe apa Vasluiului” ${ }^{3}$ (XXV, p. 200, original românesc).

Anul 1640: parte din Miclești „care se numește Berindieștii, ce este în ținutul Vaslui, pe rîul Vaslui" (XXV, p. 426, original slavon).

Anul 1643: satul Popeștii „din capul părăului Vasluiului [...] acest sat, Popeștii, din obîrşiia pîrîului Vasluiu [...] cu moară și cu mănăstirea Trestiiana"14 (XXV, p. 142, copie din 1825).

Anul 1644: „satul Rusenii și cu jumătate din vadul de moară care este pe rîul Vasluiului” ${ }^{15}$ (XXVII, p. 429, original slavon).

Anul 1644: satul Totoiești „cu vad de moară la rîul Vaslui”16 (XXVII, p. 385, original slavon).

Anul 1678: „o seliște anume Strahoeștii pe apa Vasluiului în sus de tîrg în ținutul Vasluiului” (Ghibănescu, VIII, p. 254, document slavon).

\footnotetext{
${ }^{7}$ Șerbotești, sat pe cursul mijlociu al Vasluiului.

${ }^{8}$ Brebi, loc <la Popești, comuna Miclești, județul Vaslui>.

${ }^{9}$ Dealul Vasluiului în hotarul satului Prigorceni, ținutul Vaslui, pe pîrîul Sărata; numele dealului este de la numele tîrgului. Pentru Glod, cf. pîrîul Glodul, afluent drept al Vasluiului, lîngă satul Solești.

${ }^{10}$ Lîngă Șchei, Ferești, pe pîrîul Sărata.

${ }^{11}$ Poiana Cîrnului, astăzi Poiana, comuna Schitul Duca, sat pe cursul superior al rîului Vaslui.

${ }^{12}$ Fost sat pe Vaslui <probabil lîngă Codăiești și Movila lui Burcel>.

${ }^{13}$ Pe cursul superior al Vasluiului.

${ }^{14+}$ Popeștii, fost sat lîngă Pocreaca, comuna Schitul Duca, județul Iași; ${ }^{+}$Trestiana, fost sat (și mănăstire) în partea de V a satului Poiana, comuna Schitul Duca.

15 *Rusenii, fost sat pe Vaslui <lîngă Mircești, comuna Tăcuta, j. Vaslui〉.

$16 *$ Totoieștii, fost sat pe Vaslui <lîngă Burcelu, înglobat în Codăiești>.
} 
Anul 1686: „Șerbești [...] cu vadu de moară într-apa Vasluiului” ${ }^{17}$ (Ghibănescu, V, p. 330).

Anul 1704: Mihai Racoviță miluiește pe Panaite pîrcălabul „cu un vad de moară în apa Vasluiului improtiva tîrgului" (Ghibănescu, XV, p. 124).

Anul 1796: Egumenul Mănăstirii Dobrovăț dă la schimb hatmanului C. Ghica „un vad de moară pe apa Vasluiului la tîrgu Vasluiului" (Ghibănescu, XV, p. 184). Schimbul este confirmat la 1805 de C. Moruz, cu păstrarea formulei: „un vad de moară pe apa Vasluiului la tîrgu Vasluiului” (p. 212).

După cum se poate constata din seria atestărilor de mai sus, forma primară a hidronimului pare a fi fost singurul nume utilizat în documentele istorice, începînd din secolul al XV-lea pînă la 1800, pentru desemnarea rîului care curge pe lîngă orașul Vaslui și care se varsă în Bîrlad în aval de oraș.

\subsection{Documente cartografice și lucrări geografice}

Cercetarea surselor geografice pare să aducă un supliment de informație, cel puțin asupra componenței cîmpului hidronimului Vaslui, dacă nu și referitor la concurarea formei de bază a acestuia de către forma sa diminutivală.

2.2.1. Astfel în ATLAS MOLD. de la sfîrşitul secolului al XIX-lea sînt atestate următoarele forme:

a. Pîrîul Vasluiu, la Schitul Ducăi, Poiana Cîrnului și mai în aval, la Pribești, Deleni;

b. Pîrîul Vasluețu, cracul stîng constitutiv al Vasluiului, la $\mathrm{N}$ de satul Poieni, dar și cracul drept constitutiv al Vasluiului, la $S$ de satul Poieni;

c. Şesu Vasluiului, între satele Solești și Șerbotești, la N de orașul Vaslui, pe rîul Vaslui, în amonte de satele Moara Grecilor și Moara Domnească ${ }^{18}$.

Atestarea diminutivului pentru desemnarea unui afluent de la izvoarele rîului, sau a afluenților constituienți ai acestuia, este un fapt cu totul normal, am spune chiar un „loc comun” în componența unui cîmp toponimic dezvoltat în jurul unui hidronim.

2.2.2. Lucrările geografice din a doua jumătate a secolului al XX-lea confirmă suplimentul de informație asupra componenței cîmpului analizat, oferit de harta din 1895, cu o contribuție în ceea ce privește cursul inferior al Vasluiului.

ROM.: Vaslui, rîu.

HARTA MIL. din 1962:

a. Vaslui, rîu, numit astfel pînă la satele Poieni și Schitul Duca;

b. Vasluieț, cracul stîng constitutiv al Vasluiului, care se varsă în acesta la satul Poieni;

c. Vasluieț, cursul inferior (?) al rîului Vaslui, în aval de orașul Vaslui, pînă la confluența sa cu rîul Bîrlad.

TTRM, I ${ }_{4}$, s.v. Vasluiul: mare afluent stîng al rîului Bîrlad (în orașul Vaslui, mun. Vaslui, j. Vaslui) - de la harta lui Dimitrie Cantemir din 1716 pînă la cea a lui Bawr din 1781.

TTRM, I ${ }_{3}$, s.v. Vasluiul: Afluent stîng al rîului Bîrlad.

Gugiuman (1988, p. 313): Vaslui, pîrîu de 64 km, afluent stîng al rîului Bîrlad, la marginea de $\mathrm{SE}$ a municipiului Vaslui.

Așadar în documente și în sursele cartografice, ca și la geografi apare numele Vaslui pentru cursul principal de apă, forma diminutivală fiind eventual utilizată pentru a denumi un afluent al acestuia în zona de la izvoare. În una din surse, forma diminutivală a numelui este utilizată și pentru desemnarea zonei de vărsare a pîrîului, în dreptul municipiului omonim.

\footnotetext{
${ }^{17}$ La E de Codăiești.

${ }^{18} \mathrm{O}$ atestare indirectă a utilizării hidronimului Vaslui și în acest sector al rîului în discuție.
} 


\subsection{Hidronimul Vaslui /Vasluieț în surse moderne}

În surse moderne (care consemnează forme orale la origine) este atestată, în mod neașteptat, utilizarea extinsă a hidronimului Vasluiețul pentru desemnarea întregului curs principal de apă, de la izvoare pînă la vărsare, prin substituirea totală a denumirii vechi.

2.3.1. Prima schimbare totală de perspectivă denominativă este oferită paradoxal de o lucrare contemporană cu ATLAS MOLD., care prezerva încă forma inițială a hidronimului (vezi supra). Este vorba de MDG, în care rîul în cauză apare denumit în diverse volume numai cu forma diminutivală a hidronimului.

Pîrîul Dobrovățul, care izvorăște din Dealul Bîrnova, „se varsă în pîrîul Cuțigna ${ }^{19}$ și apoi împreună în Vaslueț”20 (III, p. 158/2).

Bîrladul trece prin comunele Rădiul și Vasluiul „unde primește pîrîul Racova în dreapta și Vasluețul în stînga"21 (V, p. 722/3).

„Văi cu pîrîe, care se termină treptat pe o parte a pîrîului Vasluețul, precum sunt: Valea Șerbești, Valea Ferești, Olănești”22 (V, p. 722/1).

Într-un fragment de prezentare a orografiei județului Vaslui: „culmea ce pleacă printre pîraiele Vasluețul și Dobrovățul [...] și Codăești, unde se face și confluența acestor două pîrîie"23. O altă culme, paralelă cu pîrîul Vasluieț, „se termină la confluența Vasluețului în rîul Bîrlad [unde] e situat și orașul Vaslui” ${ }^{24}$ (V, p. 722/1).

Comuna urbană Vaslui este „situată pe capătul de sud al dealului Delea în unghiul format de confluența pîrîului Vasluețul cu rîul Bîrladul. [...] Pe partea de est [a orașului Vaslui] se deschide valea întinsă a Crasnei, prin care curge pîrîul Vasluețul ce, mai în jos de oraș, se aruncă în apa Bîrladului” (V, p. 723/2).

„Sărata, pîrîul [care curge prin] comuna Ferești și [...] comuna Dănești [...] străbate teritoriul satului Moara Domnească [...] se varsă în pîrîul Vasluețul”25 (V, p. 338/2).

2.3.2. Noua perspectivă denominativă este confirmată de alte surse, care au la bază (și) informații orale, locale.

Rîul Vasluieț, afluent al Bîrladului, este principalul curs de apă din satul Muntenii de Sus, județul Vaslui (NALR-DATE, p. 298).

Pentru oficialii primăriei comunei Schitul Duca, județul Iași rețeaua hidrografică este „formată din ape de suprafață, respectiv Slobozia și Vasluieț, cu afluenții săi Tabăra, Pocreaca și Vasluieț" ${ }^{6}$ (primariaschituduca.ro).

Pe harta satului Dumitreștii Gălății, rîul Vaslui este numit Vasluieț, numele păstrîndu-se pînă la vărsarea sa în rîul Bîrlad, puțin mai sus de gura Crasnei. În dreptul orașului Vaslui nu apare nici o

\footnotetext{
${ }^{19}$ În HARTA MIL. este numit Rediul în cursul său inferior.

${ }^{20}$ La 1503 DRH, A, III ne oferea o atestare în care Dobrovățul era afluent al unui rîu numit Vaslui: „unde cade Dobrovățul in Vaslui", v. supra.

${ }^{21}$ Așadar afluentul Bîrladului din dreptul orașului Vaslui nu este rîul Vaslui, ci Vasluiețul.

${ }^{22}$ Pîraiele Șerbești, Ferești, Olănești sînt afluenți ai rîului Vaslui, vezi harta.

${ }^{23}$ La Codăiești este confluența Dobrovățului cu Vasluiul, deci Vasluiețul din fragmentul citat substituie hidronimul originar.

${ }^{24}$ Vezi nota 21.

${ }^{25}$ Vezi supra atestarea de la 1487: satul Cîrjanii „pe Sărata, partea dinspre Vaslui”, din care se poate deduce că pîrîul în discuție desemna un afluent al Vasluiului.

${ }^{26}$ Aici apare omonimia, nesupărătoare pentru autorii site-ului, dintre numele cursului principal Vasluiețul și afluentul său de la izvoare, numit tot Vasluiețul. Cu alte cuvinte, Vasluiețul se varsă în Vasluieț.
} 
diferențiere între un curs nou al rîului Vaslui, sub tîrg, și cursul vechi, mai spre est (adică Vasluiul Vechi sau Vasluiețul [Vechi]). Rîul pare să includă și cursul numit Vasluiețul în harta militară și în Atlasul rutier, unde apare (?) distincția dintre rîul Vaslui (cursul principal) și Vasluiețul din cursul inferior al rîului (dumitrestii-galatii-is.pe-harta.ro).

Harta online de pe site-ul Google prezintă aceeași situație ca celelalte hărți de pe site-urile satelor, cu utilizarea formei diminutivale a hidronimului pentru a desemna rîul numit în documentele istorice și în lucrările geografice doar Vaslui (google.com/maps).

\section{Evoluția raportului de desemnare în cazul hidronimului Vaslui}

Comentînd informațiile oferite de sursele prezentate mai sus, observăm că documentele vechi și sursele cartografice propriu-zise prezintă situația normală a cîmpului toponimic discutat, și anume hidronimul Vaslui, alături de care apare derivatul diminutival Vasluiețul desemnînd cracul stîng constitutiv al rîului Vaslui, la care unele surse cartografice adaugă și hidronimul Vasluiețul desemnînd de data aceasta cursul inferior al rîului principal sau eventual o deviere a acestuia în cursul său inferior. Denumirea iniţială a rîului apare începînd de la cele mai vechi documente și se menține în desemnarea cursului principal de apă, pe care era situat de altfel și tîrgul omonim, pînă la sfîrșitul secolului al XVIII-lea. Această situație este susținută și continuată pînă în prezent și de sursele cartografice serioase, fără excepție.

3.1. Situația pare a se schimba radical începînd cu surse moderne care prezintă în fapt informații culese din teren, ceea ce intrigă cu atît mai mult: în aceste surse, începînd cu sfîrșitul secolului al XIX-lea, numele iniţial al rîului este substituit prin forma sa diminutivală, utilizată pînă atunci pentru desemnarea fie a unui afluent de la izvoare, fie a unui crac desprins din cursul principal în zona de la vărsare.

Am găsit, în acest sens, confirmarea circulaţiei denumirii hidronimului în forma diminutivală pentru cursul principal de apă în NALR-DATE, p. 298, locuitorii din Muntenii de Sus denumind rîul care curge pe teritoriul satului lor Vasluieț, și nu Vaslui, calificîndu-l drept principal afluent al Bîrladului. Situația este menţionată, după cum am afirmat anterior, încă de la 1900, cînd oraşul Vaslui este localizat ca find aşezat „în unghiul format de confluența pîrîului Vasluețul [și nu Vasluiul] cu rîul Bîrladul” (MDG, V, s.v.), nefiind menționat deloc rîul Vaslui, cum ne-am fi așteptat. În aceeași sursă găsim o mențiune suplimentară a aceleiași situații stranii:

„Pe partea de est se deschide valea întinsă a Crasnei, prin care curge pîrîul Vasluețul, ce, mai în jos de oraș, se aruncă în apa Bîrladului."

Așadar Vasluiețul nu ar fi un afluent al vreunui pîrîu numit Vaslui, cum ar fi firesc, ci al oricărui alt pîrîu numit oricum (în cazul nostru, Bîrladul), dar nu Vaslui. Dacă în cazul Corozelului, și el afluent nu al vreunui Corod, ci al Bîrladului, la fel ca Tecucelul, s-a găsit explicația situației aparent bizare, în cazul Vasluiețului, după cum am menționat supra, nu se poate aplica aceeași explicaţie.

3.2. Primul document istoric care introduce în structura cîmpului forma diminutivală a hidronimului pare a fi din anul 1783, în care este consemnat un litigiu între Mănăstirea Dobrovăț (cu mitocul ei, Mănăstirea Lipovăț de lîngă Vaslui) și diacul Clement pentru un vad de moară în apa Vasluiului în zona tîrgului. Clement invocă un hrisov pe care îl are de la Mihai Racoviță din anul 1705 pentru un vad de moară pe apa Vasluiului lîngă tîrg, reclamînd faptul că mănăstirea îi trage apa de la moară, deși aceasta nu are vreun drept în acest loc, ci eventual în Vasluețul cel Vechi (Ghibănescu, XV, p. 156). Această sintagmă redundantă din punctul de vedere al mărcilor de diferențiere faţă de toponimul de bază, adică cumulînd marca sufixală cu determinarea adjectivală, se clarifică în cercetarea ordonată de domnitor pentru stingerea conflictului. Are Mănăstirea Lipovăț vreun drept de a-și face moară în Vasluiul Nou, unde și-a făcut Clement moara, sau în apa Vasluețului celui Vechiu, cum pretinde ultimul? Tîrgoveții vasluieni nu cunosc răspunsul, sau cum consemnează documentul „nu s-au aflat nimeni a ști nici pentru apa Vasluiului de cînd s-au stricat și 
s-au făcut Vasluiul Nou, alții nu știu fără numai un Ion Iftodi [care] ar fi auzit cum că din zilele lui Ștefan Voevod s-au mutat Vasluiu cel Vechiu și s-au făcut cel nou" (Ghibănescu, XV, p. 156). În fapt dania către Mănăstirea Lipovăț se dovedește a fi, în același document, mai veche, de la Miron Barnovschi din 1628, este drept că atunci nu apărea încă diferențierea între hidronimele Vaslui și Vasluieț, dania lui Barnovschi fiind pentru „o moară gata în apa Vasluiului” (Ghibănescu, XV, p. 158).

Continuarea cercetării litigiului aduce noi elemente cu ajutorul memoriei colective care pare să conserve în mod miraculos amintirea acelui eveniment petrecut în urmă cu cîteva secole, în perioada în care tîrgul Vaslui constituia una din reședințele lui Ștefan cel Mare, avînd calitatea de tîrg domnesc.

„Întrebînd pe oameni de cînd s-au abătut apa Vasluiului din matca ei de merge pe supt tîrgu, și oamenii ni-au mărturisit [...] că din zilele lui Ștefan Voevod cel Bătrîn au abătut apa săpînd hendichi ${ }^{27}[. .$.$] și au îndreptat-o pe sub tîrgu pe unde merge acum Vasluiul” (Ghibănescu, XV,$ p. 158).

Evenimentul pare plauzibil, dar nu poate fi legat de existența în amonte de această deviere a unui iaz domnesc, probabil pe locul actualului sat Moara Domnească:

„[Oamenii] au arătat că au fost tîrgul vechiu mai denainte de la casele domnești în sus podișul păn la iazul domnesc fiind tot locuri de casă” (Ghibănescu, XV, p. 158).

Evenimentul modern, din vremea lui Clementie, este legat de cel din vremea lui Ștefan:

„În coada iazului morii lui Clementie unde este ruptura iazului domnesc de unde s-au abătut apa, c-au fost niște șarampoi” (Ghibănescu, XV, p. 158).

Pentru pitorescul ei mai menționăm și rezolvarea problemei localizării vadului de moară primit ca danie de Mănăstirea Lipovăț de la Miron Barnovschi, sugerată de document printr-un exercițiu de logică:

„De va vre [cineva] să facă moară în gîrla ce să numește Vasluețul Vechiu poate să facă, dar a umbla numai cînd a vărsa Vasluiul și apoi a șide uscată după cum este și acum gîrla sacă” (Ghibănescu, $\mathrm{XV}$, p. 158).

Revenind la informația esențială despre perechea hidronimică Vaslui / Vasluieț, menționăm informația lui Ghibănescu despre planul tîrgului Vaslui din același an 1783: „Vasluiul Vechiu venea mai spre răsărit spre Dealul Bustiii ${ }^{28}$, iar Vasluiul nou curge supt Dealul Tîrgului” (XV, p. 158).

În HARTA MIL. este reprezentată în amonte de satul Moara Domnească o bifurcare a pîrîlui Vaslui, un crac paralel la E de cursul principal, dar care reintră în acesta tot în amonte de Moara Grecilor.

Iar la 1725 descrierea hotarului Tătărașilor despre Vaslui confirmă ceea ce putem vedea mai tîrziu cu cîteva decenii în planul tîrgului de la 1783: „peste șes spre răsărit peste apa Vasluiului, pe Vasluiul cel Bătrîn pînă în obîrșiea topilelor [...] și de acolea pe drumuşor peste Valea Bustei” (Ghibănescu, XV, p. 131).

Apariția iazului domnesc din sus de tîrg ar putea fi legată de existența unei mori domnești în amonte de tîrg (cf. satul actual Moara Domnească), dar explică mai greu devierea Vasluiului în dreptul tîrgului Vaslui, adică în aval de locul cu mori (Moara Domnească, Moara Grecilor). Pentru a-şi îndeplini funcția, aceea de a alimenta iazul unei mori, devierea unei ape curgătoare se face în amonte de moară și, evident, de iazul morii. Acțiunea de regularizare a rîului care pare a fi avut loc în timpul domniei lui Ștefan cel Mare a putut avea alte rațiuni, în plus trebuie menționat și faptul că în zona de vărsare, Vasluiul are și, probabil, a avut un curs neregulat, din cauza morfologiei terenului.

\footnotetext{
${ }^{27}$ Din tc. hendek „șanț de apărare, metereze, șanț”; să fi fost un șanț săpat de Ștefan cel Mare pentru apărarea tîrgului, prin care s-a deviat și Vasluiul?

${ }^{28}$ Pe coasta de E a acestuia se află satul Băhnarii de la E de tîrgul Vaslui (MDG, II, 85/3).
} 
3.3. Situații similare, din cauze similare, par a fi sugerate de atestarea denumirii Vasluiul Vechi sau Bătrîn și în alte sectoare ale pîrîului, în speță în cursul său superior, deci fără legătură cu ceea ce s-a întîmplat în cursul inferior. Astfel la 1644 postelnicul Grigorie cumpără „tot satul Ruseni, din același ținut [Vaslui] [...] însă cu jumătate din vad de moară, și cu moară gata, și cu a patra <parte> din Poiana Cîrnului și cu bucovină, din locul Șerbeștilor în jos pînă [loc liber], și la șes pe unde a fost Vechiul Vaslui” (DRH, A, XXVIII, p. 386). $\mathrm{Nu}$ considerăm că avem aici deja extensia numelui concurent al hidronimului inițial Vaslui (Vasluiul Vechi ca sinonim pentru Vasluiețul), ci de desemnarea unei porțiuni din cursul rîului reprezentînd vechea albie a acestuia, secată în urma unei devieri a cursului din cauze antropice sau naturale.

Așadar am putea avea o cauză multiplicată, am zice, a substituirii vechiului hidronim Vaslui prin forma diminutivală Vasluieț.

\section{Comparația cu alte tipuri de diferențiere hidronimică}

Acest tip de diferențiere a fost explicat de Dragoș Moldovanu (2014; vezi supra) cu referire la cazul cîmpului toponimic al Corodului, care a analizat evoluția relației dintre localitatea Corod și pîrîul Corozel pe care aceasta este situată actualmente.

4.1. Comentariul nostru are rolul de a aduce cîteva precizări referitoare la deosebirea dintre acest tip de diferențiere toponimică și cel analizat de noi. Dacă omonimia relativă cu oiconimul Vaslui poate fi admisă drept cauză, secundară și în acest caz, a extensiei formei diminutivale Vasluiețul în defavoarea formei normale Vasluiul a hidronimului, mai veche, cauza inițială pare a fi alta aici, pentru că în cîmpul luat în discuție opoziția primară Vaslui vs Vasluieț privește doar zona de la izvoare a pîrîului, fiind improbabilă o extensie a denumirii unui crac constituient asupra întregului curs de apă. $\mathrm{Cu}$ atît mai mult cu cît este atestată documentar apariția celeilalte opoziții primare, din cursul inferior al rîului, Vasluiul [Vechi] vs Vasluiul Nou, ulterior Vasluiețul vs Vasluiul. Pentru înțelegerea variantelor denominative Vasluieț, Vasluiul Vechi, Vasluiețul Vechi utilizate în desemnarea albiei vechi a Vasluiului, cf. comentariul pentru Tecucel, Tecucelul Sec, Tecuciul Sec în Cojocaru (2015).

4.2. O ultimă întrebare ar fi aceea asupra impactului în planul denominației toponimice a schimbării din aspectul fizico-geografic al referentului. Cît de repede se poate reflecta o modificare fizico-geografică în inventarul toponimic al unei zone? Evenimentul presupus din vremea lui Ștefan cel Mare pare să fi avut efect în planul toponimic abia după vreo două secole.

\section{Concluzii}

5.1. Am numit-o diferențiere atipică, pentru că este diferită de tipologiile analizate pînă acum:

a. Nu este o extensie a unei forme diminutivale a hidronimului de la afluentul principal la cursul principal de apă (în etape sau nu: hidronimul *Corod vs hidronimul Corozel; hidronimul *Tecuci vs hidronimul Tecucel $\left.^{29}\right)$.

b. Nu este vorba nici de păstrarea formei diminutivale a hidronimului de către afluentul secundar însoțită de dispariția-de fapt substituirea - formei de bază a numelui care desemna cursul principal ( ${ }^{*}$ Bîrzava $\rightarrow\left(z u l\right.$ vs Bîrzăuţa $\left.{ }^{30}\right)$ sau, mai complicat, și de reapariția denumirii de bază la afluentul secundar $\left({ }^{+}\right.$Sagna $\rightarrow$ Vulpăşsşti vs Sagna, fost ${ }^{+}$Săgnița $\left.{ }^{31}\right)$, fenomen intermediat de existența localității cu nume omonim situată la confluența celor două cursuri de apă.

\footnotetext{
${ }^{29} \mathrm{O}$ evoluție mai complexă o găsim în cazul perechii Voitin / Voitinel, ambele avînd calitatea atît de hidronim, cît și de oiconim, pentru care vezi MDTM, I, s.v.

${ }^{30}$ Despre „principiul metodologic al reconstrucției unor hidronime neatestate plecând de la diminutivele lor, care desemnează afluenți”, cf. Moldovanu (2010, p. 27-28), care discută și perechea hidronimică *Bîrzava vs Bîrzăuţa.

${ }^{31}$ Discuția problemei la Cojocaru (2015, p. 76-78).
} 
c. Este vorba, aşadar, tot de o extensie, ca în cazul a., dar nu a denumirii unui afluent, principal sau nu, ci a numelui unui crac ce reprezenta cursul vechi al unei ape. Facem mențiunea că la toate aceste tipuri de extensie hidronimică oiconimul din cîmp, numele localității a putut constitui un factor favorizant, prin omonimia dintre acesta și hidronim (Moldovanu, 2014, p. XII), în cazul cîmpului Sagna de sub b. prezența oiconimului find chiar o condiție sine qua non a procesului.

5.2. După cum se poate observa din argumentația noastră, în nici unul din tipurile de diferențiere toponimică menționate aici nu s-a invocat prezența unui sufix cu funcție exclusiv toponimică, dimpotrivă, în acest proces au fost implicate mai multe sufixe utilizate în lexicul comun: -eț, dar și -el, -iţă. Pe de altă parte, analogia cu forma pruteț '[orice] crac sau baltă [?] a Prutului' nu am găsit-o pertinentă, deoarece situaţia cîmpului toponimic al hidronimului Vasluiul este diferită de cea a Prutului. În primul caz, forma diminutivală, Vasluieț, este atestată cu funcția de desemnare a unui pîrîu constituient al cursului principal, așadar situat în zona de la izvoare a acestuia, și nu a oricărui crac al Vasluiului. În replică, nu cunoaștem vreun afluent al Prutului, constituient—adică de la izvoare—sau nu, care să se numească Pruteţul, în afara porțiunilor de curs vechi sau a bălţilor formate prin revărsarea Prutului. O eventuală analogie cu situația prutețelor ar fi acceptabilă doar pentru zona de vărsare a Vasluiului, acolo unde cursul acestui rîu se ramifică într-unul mai vechi și altul mai nou. Dar și aici fenomenul este diferit, deoarece documentele par a atesta intervenția umană într-o acțiune de regularizare a cursului de apă, cu alte cuvinte o cauză antropică.

\section{Bibliografie}

ATLAS MOLD. = Atlasul Moldovei (1:50 000), Institutul Geografic al Armatei, București, 1892-1898.

Cojocaru, V. (2015). Micul dicționar toponimic al Moldovei, structural și etimologic și cerințele teoriei cîmpurilor toponimice, în „Anuar de lingvistică și istorie literară”, LV, p. 73-80.

DRH, A = Documenta Romanic Historica. A. Moldova, I-XXVII, București, 1975-2006.

Ghibănescu, Gh. (1906-1933). Surete și izvoade, vol. I-XXV, Tipografia Dacia, Iași.

Gugiuman et al. (1988). Dicționar geografic al județului Vaslui, I. Gugiuman, V. Cîrcotă, V. Baican, Iași.

HARTA MIL. = Harta R. S. România, executată de Direcția Topografică Militară, (1:25 000), București, 1962.

MDG $=$ Marele dicționar geografic al României, I-V, București, 1898-1902.

MDTM, I = Mic dicționar toponimic al Moldovei, structural și etimologic. Partea I. Toponime personale (coordonator: Dragoș Moldovanu), Editura Universității „Alexandru Ioan Cuza”, Iași, 2014.

Moldovanu, D. (2010). Teoria cîmpurilor toponimice (cu aplicație la câmpul hidronimului Moldova), Editura Universității „Alexandru Ioan Cuza”, Iași, 2010.

Moldovanu, D. (2014). Introducere la MDTM, I.

NALR-DATE = Noul Atlas Lingvistic al României. Moldova și Bucovina. Date despre localități și informatori, Editura Academiei, București, 1987.

ROM. = România. Atlas rutier, de general maior ing. Vasile Dragomir, col. ing. Victor Balea, col. ing. Gheorghe Mureșanu, Gheorghe Epuran, sc. 1:350 000, București, 1981.

TTRM = Tezaurul toponimic al României. Moldova (coordonator: Dragoș Moldovanu). $\mathrm{I}_{1-2}$, Repertoriul istoric al unităților administrativ-teritoriale (1772-1988), București, 1991-1992. $\mathrm{I}_{3}$, Toponimia Moldovei în documente scrise în limbi străine (exclusiv slavona), Iași, 2004. I4, Toponimia Moldovei în cartografia europeană veche (cca 1395-1789), Iași, 2005. 